\title{
Fabrication of Polymer Organized Thin Films Containing Ruthenium Complexes
}

\author{
Tokuji MiYASHITA ${ }^{\dagger}$, Jinfeng CHEN, \\ Masahiro YUASA, and Masaya MITSUISHI \\ Institute for Chemical Reaction Science (ICRS), Tohoku University, \\ Katahira 2-1-1, Aoba-ku, Sendai 980-8577, Japan
}

(Received February 12, 1999)

\begin{abstract}
Polyion complex Langmuir-Blodgett (LB) films containing Ru(dpphen) ${ }_{3}{ }^{2+}$ (dpphen $=4,7$-diphenyl-1, 10phenanthroline) probe (Rudpphen) were prepared by spreading a mixed chloroform solution of $N$-dodecylacrylamide (DDA)- $N$-acryloxysuccinimide ( $\mathrm{SuOA}$ ) copolymer and $\mathrm{Ru}(\mathrm{dpphen})_{3} \mathrm{Cl}_{2}$ onto the water subphase at $\mathrm{pH}=11$. The $\mathrm{SuOA}$ groups undergo a hydrolysis at $\mathrm{pH}=11$ yielding the acrylate anion, which forms an ion-complex with $\mathrm{Ru}(\mathrm{dpphen})_{3}{ }^{2+}$ in the monolayer. It was found that $\mathrm{Ru}(\mathrm{dpphen})_{3}{ }^{2+}$ is located in the hydrophobic portion of the monolayer at the air/water interface. The monolayers of $\mathrm{p}(\mathrm{DDA} / \mathrm{Rudpphen)}$ could be successfully transferred on a quartz substrate with less than 14 mol \% Ru(dpphen $)_{3}{ }^{2+}$ content. The UV-vis spectroscopy and X-ray diffraction confirmed that the Ru(dpphen) ${ }_{3}{ }^{2+}$ molecules were densely packed and uniformly distributed in the polyion complex LB films. The properties of $\mathrm{p}(\mathrm{DDA} / \mathrm{Rudpphen})$ monolayer and LB films were compared with p(DDA/Rubpy) LB films (bpy $=2,2$ '-bipyridine), which have been previously reported. The luminescence quenching of $\mathrm{Ru}(\mathrm{dpphen})_{3}{ }^{2+}$ by oxygen was also discussed.
\end{abstract}

KEY WORDS LB films / Ruthenium / Polyion Complex / Polymer / Acrylamide /

Langmuir-Blodgett (LB) films, which are prepared from the deposition of a monolayer spread on water surface onto solid supports, such as silicon wafers, are expected to provide a molecular organized assembly. Various kinds of amphiphilic materials such as long-chain fatty acids have been utilized. These LB films, however, exhibit weak physical and thermal stability. Furthermore, the aggregation of chromophores in low molecular weight LB films often causes a serious problem for constructing uniformly organized assemblies. We have continued to study the preparation of polymer LB films using alkylacrylamide polymers. Furthermore, various functional groups have been incorporated into polymer films as a comonomer of $N$-dodecylacrylamide (DDA) polymer, which has an excellent ability to form a stable LB multilayer. ${ }^{1,2}$

For example, the polymer LB films containing several aromatic chromophores have been prepared for the purpose of investigating the photochemical behavior of the chromophores located at a regulated distance in the organized assemblies. ${ }^{3}$ The efficient energy migration was found in $\mathrm{p}(\mathrm{DDA} / \mathrm{VCz}) \mathrm{LB}$ films, ${ }^{4}$ and the pyrene moiety well worked as a probe to characterize the molecular environment of the LB films. ${ }^{5}$ In addition, polymer LB films using copolymers of DDA with ferrocene derivatives and with ruthenium complexes, were fabricated to investigate their electrochemical properties, in particular, of their hetero-deposited LB films. ${ }^{6}$ Recently we have reported another approach to fabricate functionalized polymer LB films, which is based on the replacement reaction of an active ester moiety ( $N$ acryloxysuccinimide, SuOA) at the monolayer interface. This method allows us to incorporate a variety of functional groups, such as bioactive groups, which is difficult to incorporate by copolymerization method, mainly due to electronic and/or steric factors. ${ }^{7}$

As a deposition technique of LB films, a polyion complex method has been reported by several research

\footnotetext{
${ }^{\dagger}$ To whom correspondence should be addressed.
}

groups ${ }^{8-14}$ a charged surfactant is spread onto a subphase containing oppositely charged polyelectrolyte, resulting
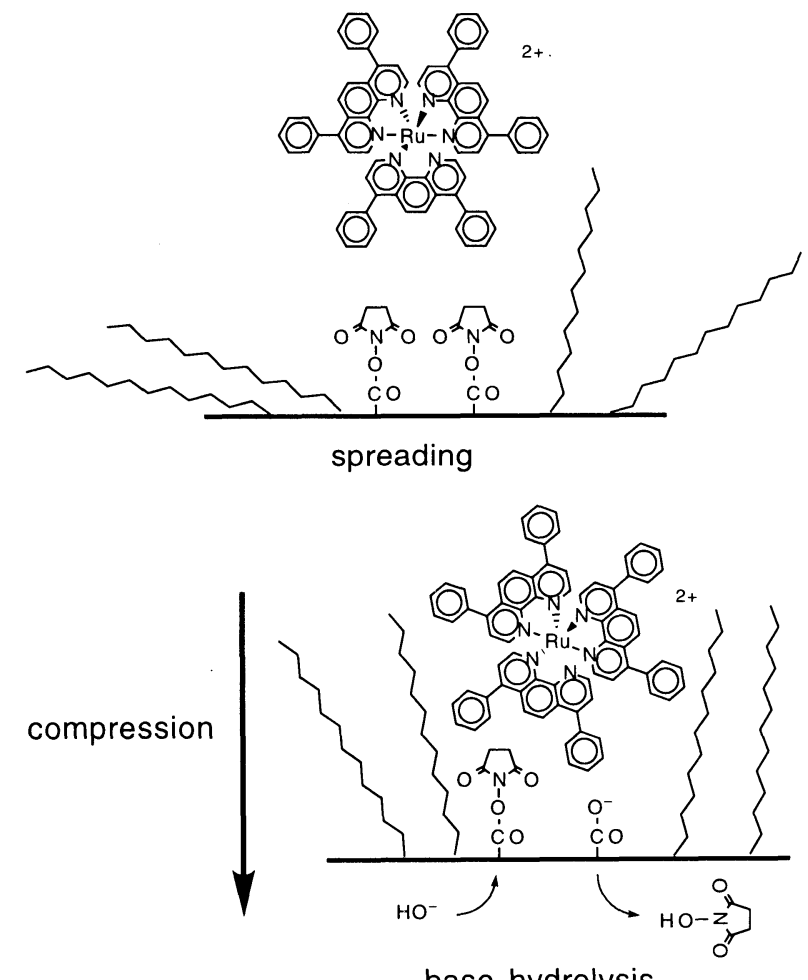

base hydrolysis

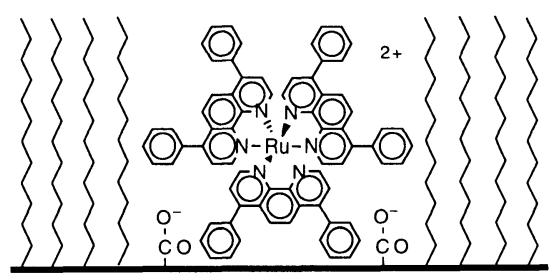

polyion complex formation

Figure 1. Schematic illustration for the formation of polyion complex LB monolayer containing $\mathrm{Ru}(\mathrm{dpphen})_{3}{ }^{2+}$. 


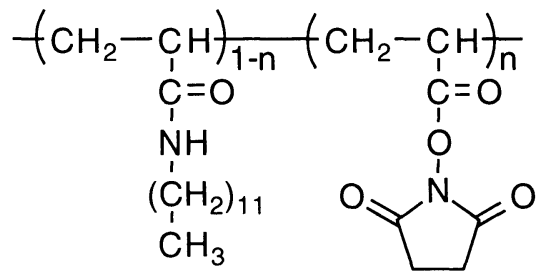

\section{$\mathrm{p}(\mathrm{DDA} / \mathrm{SuOA})$}

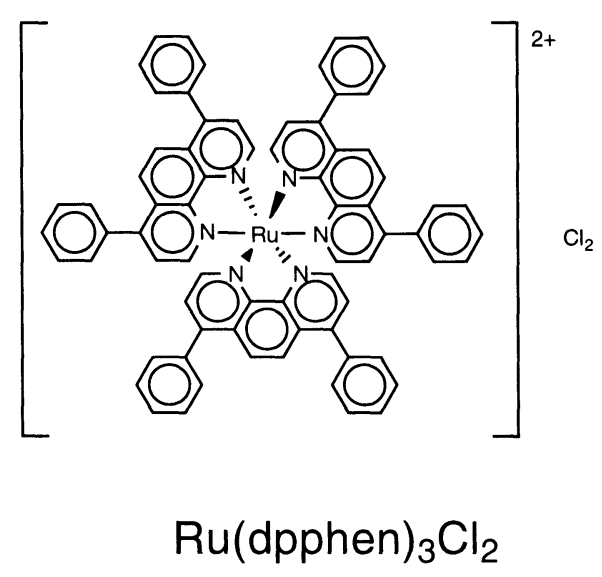

Figure 2. Structure of copolymer $\mathrm{p}(\mathrm{DDA} / \mathrm{SuOA})$ and $\mathrm{Ru}(\mathrm{dpphen}){ }_{3} \mathrm{Cl}_{2}$.

in the improvement of the film stability. In the current study, we attempt to prepare LB films containing bulky $\mathrm{Ru}(\mathrm{dpphen})_{3}{ }^{2+}$ group by a modified polyion complex method (Figure 1). First, p(DDA/SuOA) is spread with $\mathrm{Ru}(\text { dpphen })_{3}{ }^{2+}$ on the subphase at $\mathrm{pH}=11$. The SuOA moieties undergo hydrolysis yielding acrylate anions on the water surface. By compressing the mixed monolayer, a stable polymer monolayer with $\mathrm{Ru}(\mathrm{dpphen})_{3}{ }^{2+}$ is formed as a polyion complex. The LB films fabricated from the transfer of the monolayer were investigated by $\mathrm{X}$-ray diffraction, UV-vis spectroscopy, and time-resolved emission measurements.

\section{EXPERIMENTAL}

\section{Materials}

$N$-Dodecylacrylamide (DDA) and $N$ acryloxysuccinimide (SuOA) monomers were synthesized as published earlier. ${ }^{7}$ DDA copolymers with SuOA $(\mathrm{p}(\mathrm{DDA} / \mathrm{SuOA}))$ were prepared by free radical polymerization in distilled toluene at $60^{\circ} \mathrm{C}$ in the presence of 2 , $2^{\prime}$ '-azobis(isobutyronitrile) as an initiator. The copolymers were purified by dissolution in chloroform, followed by precipitation in a large excess of acetonitrile. The synthesis of $\mathrm{Ru}(\mathrm{dpphen})_{3} \mathrm{Cl}_{2}$ has been reported elsewhere. ${ }^{16}$ The molecular structures of $\mathrm{p}(\mathrm{DDA} / \mathrm{SuOA})$ and $\mathrm{Ru}(\mathrm{dpphen})_{3} \mathrm{Cl}_{2}$ are shown in Figure 2. Spectroscopic grade chloroform was used for spreading monolayer on the water surface. Monolayer subphases were prepared using Milli-Q filtered water $(>17.5 \mathrm{M} \Omega \cdot \mathrm{cm})$. The $\mathrm{pH}$ of subphase was regulated using $0.1 \mathrm{M}$ phosphate or $\mathrm{NaCO}_{3}$ 1122
Table I. Characterization of copolymers, $p(D D A / R u d p p h e n) s$

\begin{tabular}{|c|c|c|c|c|}
\hline & \multirow{2}{*}{$\begin{array}{c}\text { DDA:SuOA } \\
\text { mol } \%\end{array}$} & \multicolumn{2}{|c|}{$\mathrm{p}(\mathrm{DDA} / \mathrm{SuOA})$} & \multirow{2}{*}{$\begin{array}{c}\mathrm{p}(\mathrm{DDA} / \mathrm{SuOA}) \\
\mathrm{Ru}(\mathrm{dpphen})_{3}{ }^{2+} \\
\mathrm{mol} \%\end{array}$} \\
\hline & & $M_{\mathrm{w}} \times 10^{-4}$ & $M_{\mathrm{w}} / M_{\mathrm{n}}$ & \\
\hline p(DDA/Rudpphen6) & $80: 20$ & 8.60 & 1.54 & $95: 5$ \\
\hline p(DDA/Rudpphen 14) & $67: 43$ & 11.04 & 1.42 & $88: 12$ \\
\hline
\end{tabular}

and $\mathrm{NaHCO}_{3}$ buffer solution.

\section{Preparation of Langmuir-Blodgett Films}

The measurement of surface pressure $(\pi)$ - area $(A)$ isotherms and the deposition of monolayers were carried out with an automatically operated Langmuir trough (Kyowa Kaimen Kagaku HBM-AP using a Wilhelmy type film balance). Monolayers were spread from a $1 \times 10^{-3}$ $\mathrm{M}$ chloroform solution at $15^{\circ} \mathrm{C}$ on the water surface. The monolayer was compressed by a Teflon barrier at a rate of $14 \mathrm{~cm}^{2} / \mathrm{min}$. The quartz substrate was cleaned by immersing in a 2-propanol solution, boiling in $\mathrm{HNO}_{3}$ solution, and washing with pure water. The substrate was then treated with octadecyltrichlorosilane in chloroform for $1 \mathrm{~h}$. Finally, the substrate was washed with chloroform, acetone, and pure water to remove the excess silane-coupling reagent. The monolayers were transferred onto the quartz substrate with a dipping speed of $5 \mathrm{~mm} /$ $\min$.

\section{Instruments}

The molecular weights given in Table I were obtained by gel permeation chromatography using a polystyrene standard. The molecular compositions of SuOA were determined by 'H NMR spectroscopy.

$\mathrm{X}$-ray diffraction (XRD) patterns were measured with an X-ray diffractometer (M18XHF ${ }^{22}$-SRA, MAC Science). The $\mathrm{p}(\mathrm{DDA} / \mathrm{Rudpphen)} \mathrm{LB}$ film with 40 layers deposited on a cleaned glass substrate (Matsunami) was used for the XRD measurement.

UV-vis absorption and emission spectra were measured with a Hitachi U-3000 UV-vis spectrophotometer and a Hitachi F-4500 spectrofluorophotometer, respectively.

Time-resolved emission measurements were performed using a third harmonics of Q-switched Nd:YAG laser system (Spectron, pulse width $10 \mathrm{~ns}$, repetition rate 10 $\left.\mathrm{Hz}, \lambda_{\mathrm{ex}}=355 \mathrm{~nm}\right)$. The emission was monitored by a streak camera (Hamamatsu, C4334) through a cut-off filter (Y 52). All measurements were carried out at room temperature.

\section{RESULTS AND DISCUSSION}

\section{Monolayer Behavior at the Air/Water Interface}

First, we investigated the spreading behavior of copolymers of DDA with SuOA at $\mathrm{pH}=7$ and 11 (Figure 3 ). The $\pi-A$ isotherms of $\mathrm{p}(\mathrm{DDA} / \mathrm{SuOA} 20)$ in which the content of the SuOA is $20 \mathrm{~mol} \%$ shifted toward larger areas as the $\mathrm{pH}$ increases from 7 to 11 . The expansion of monolayer can be attributed to the electrostatic repulsion between acrylate ions, since the SuOA group undergoes alkaline hydrolysis at $\mathrm{pH}=11$ and turns into an acrylate 


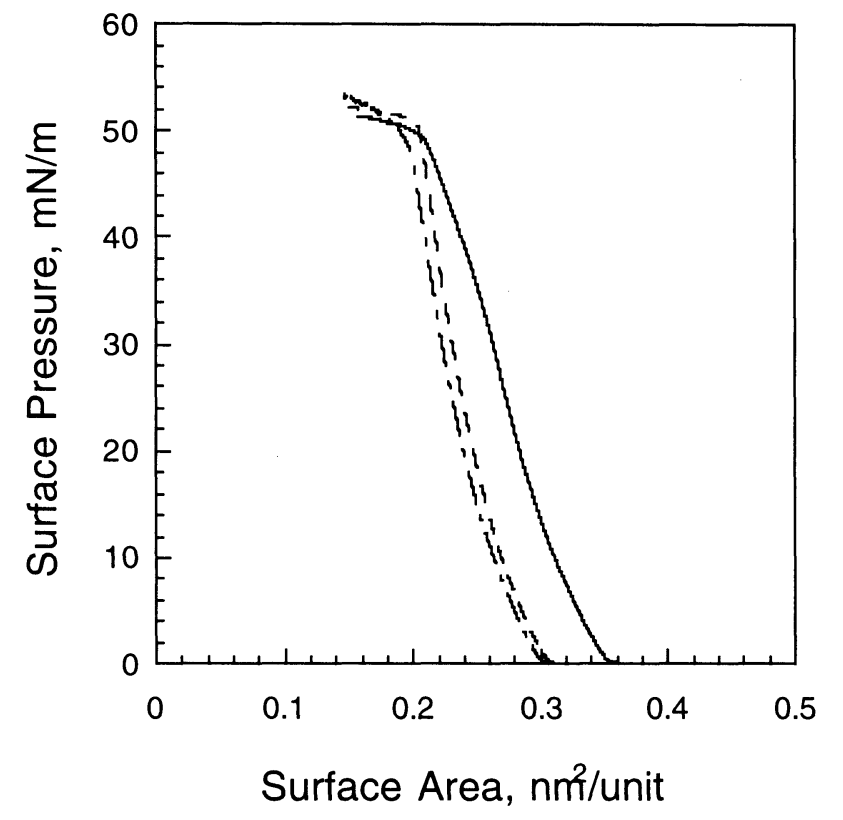

Figure 3. $\pi-A$ isotherms at $15^{\circ} \mathrm{C}$ for $\mathrm{p}(\mathrm{DDA} / \mathrm{SuOA} 20)$ monolayer at $\mathrm{pH}=7(--)$ and $\mathrm{pH}=11(--)$, and $\mathrm{p}(\mathrm{DDA} / \mathrm{Rudpphen6})$ at $\mathrm{pH}=11(-)$.

anion. Polymer LB films of p(DDA/SuOA20) were deposited on $\mathrm{CaF}_{2}$ substrates to characterize the degree of the alkaline hydrolysis using FT-IR spectroscopy. For the $\mathrm{LB}$ film deposited at $\mathrm{pH}=7$, the $\mathrm{C}=\mathrm{O}$ stretching band was observed at $c a$. $1735-1783 \mathrm{~cm}^{-1}$, which is assigned to the $N$-acryloxysuccinimide group. At $\mathrm{pH}=11$, the band was diminished and a new absorption band appeared at $1573 \mathrm{~cm}^{-1}$. This indicates that almost all the SuOA groups undergo the hydrolysis at $\mathrm{pH}=11$. The area of DDA residues is determined to be $0.28 \mathrm{~nm}^{2} /$ unit from the $\pi-A$ isotherm of the DDA monolayer, thus, the limiting area of SuOA group could be evaluated to be $0.12 \mathrm{~nm}^{2} /$ unit at $\mathrm{pH}=7$ and $0.33 \mathrm{~nm}^{2} /$ unit at $\mathrm{pH}=11$, by extrapolating the linear portion of the condensed state in the $\pi$ - $A$ curve of $\mathrm{p}(\mathrm{DDA} / \mathrm{SuOA})$ to zero surface pressure. This indicates that negatively charged monolayer of $\mathrm{p}(\mathrm{DDA} / \mathrm{SuOA})$ is formed at $\mathrm{pH}=11$ and that the electrostatic adsorption at the air/water interface will be expected in analogy with the conventional polyion complex method.

Then the chloroform solution containing $\mathrm{p}(\mathrm{DDA} / \mathrm{SuOA})$ and $\mathrm{Ru}(\mathrm{dpphen})_{3} \mathrm{Cl}_{2}$ was spread on the water subphase at $\mathrm{pH}=11$ to form a mixed monolayer of $\mathrm{Ru}(\mathrm{dpphen}){ }_{3}{ }^{2+}$ with DDA polymer. The solid line in Figure 3 shows the $\pi-A$ curve of mixed monolayer of $\mathrm{p}(\mathrm{DDA} / \mathrm{SuOA} 20)$ and $\mathrm{Ru}(\mathrm{dpphen})_{3} \mathrm{Cl}_{2}, \mathrm{p}(\mathrm{DDA} / \mathrm{Rudpphen} 6)$ at $\mathrm{pH}=11$. $\mathrm{Ru}(\mathrm{dpphen}){ }_{3}{ }^{2+}$ can interact with the acrylate anions on the water surface at $\mathrm{pH}=11$. The molecular area markedly shifts toward larger areas, indicating that the adsorption of the polyion monolayer with $\mathrm{Ru}(\mathrm{dpphen}){ }_{3}{ }^{2+}$ occurred. Furthermore, we observed no change in the area of $\mathrm{p}(\mathrm{DDA} / \mathrm{Rudpphen}) \mathrm{s}$ on keeping the surface pressure at $25 \mathrm{mN} / \mathrm{m}$. It seems that the monolayer assume dense packing and forms a condensed one.

The surface limiting area of $\mathrm{Ru}(\mathrm{dpphen}){ }_{3}{ }^{2+}$ was evaluated as follows. The area of the acrylate anion at $\mathrm{pH}=11$ (a)

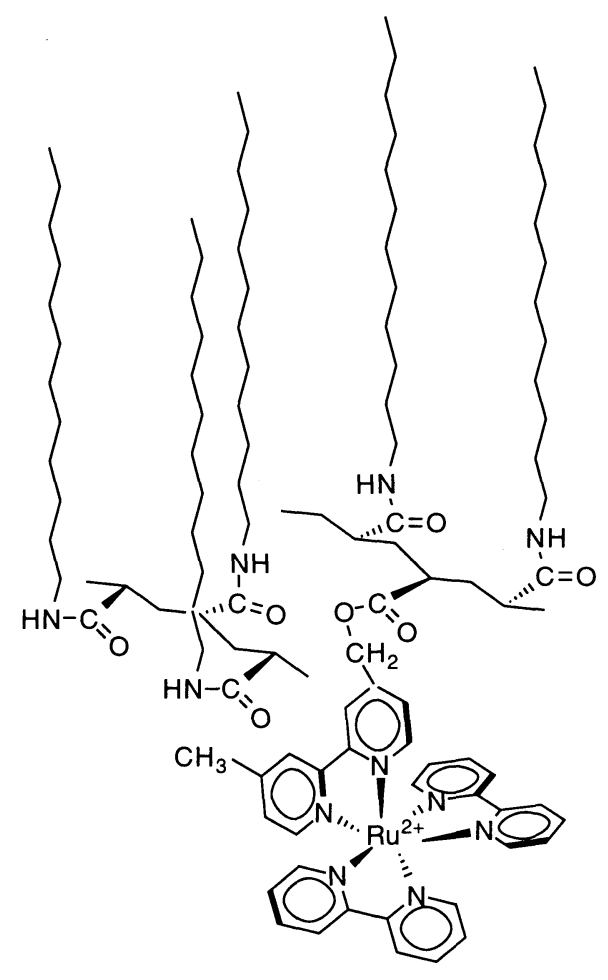

(b)

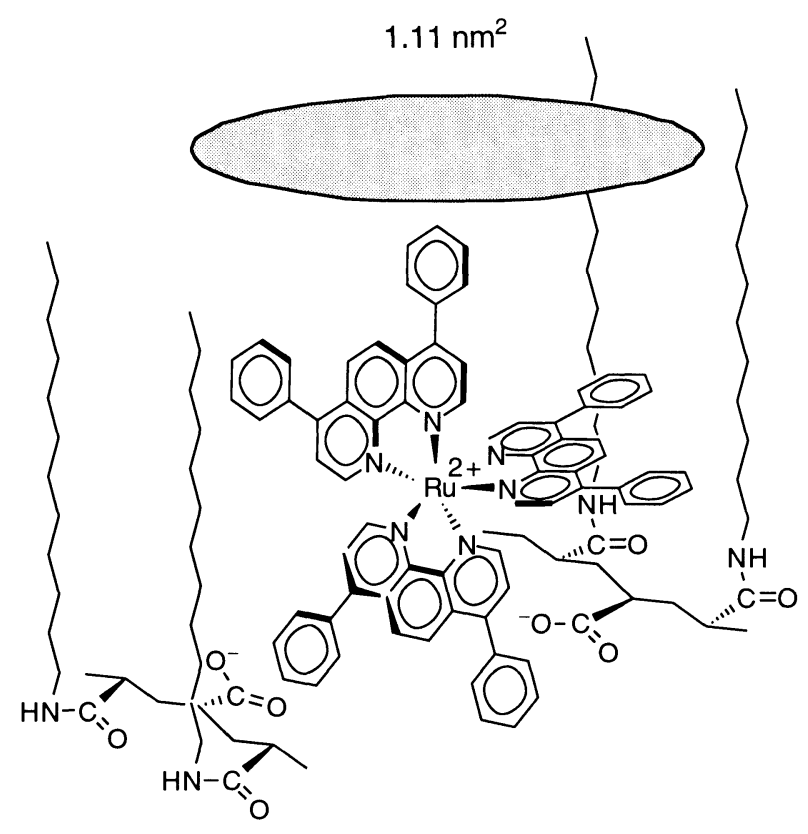

Figure 4. Schematic illustration of (a) $p(D D A / R u b p y)$ and (b) $p(D D A /$ Rudpphen) monolayers at the air/water interface.

is $0.33 \mathrm{~nm}^{2} /$ unit as mentioned above. Assuming that $\mathrm{Ru}(\mathrm{dpphen})_{3}{ }^{2+}$ is bound to two acrylate anions, the surface limiting area of $\mathrm{Ru}(\mathrm{dpphen}){ }_{3}{ }^{2+}$ group is evaluated to be $1.11 \mathrm{~nm}^{2} /$ unit. The value is almost the same as the calculated one, $1.13 \mathrm{~nm}^{2}$, which is based on a radius of 6 $\AA$ for $\mathrm{Ru}(\mathrm{dpphen})_{3}{ }^{2+} .{ }^{16}$

As a comparison, a mixed chloroform solution of pDDA 
(a)

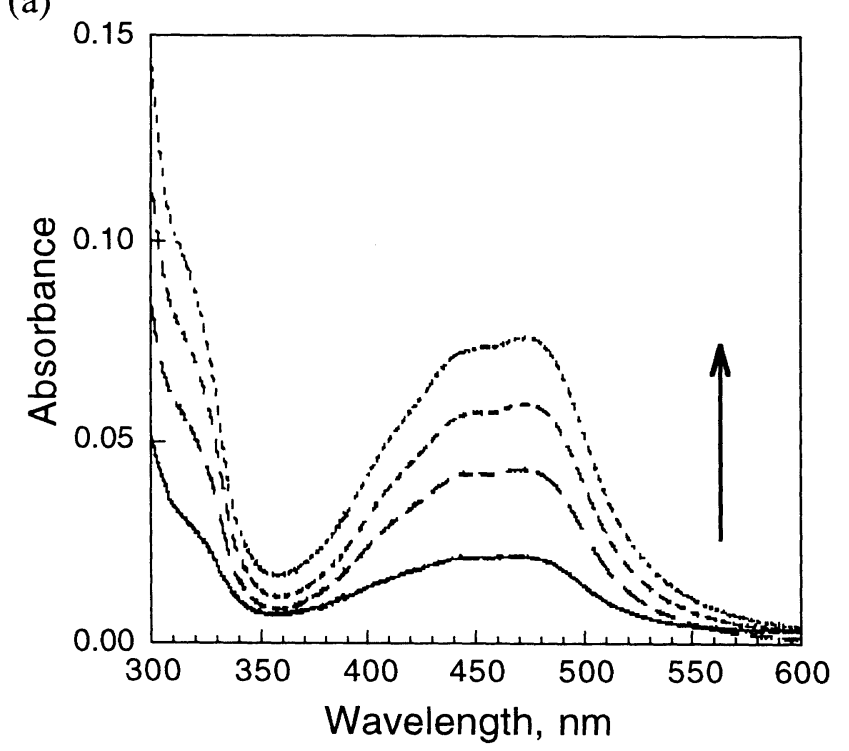

(b)

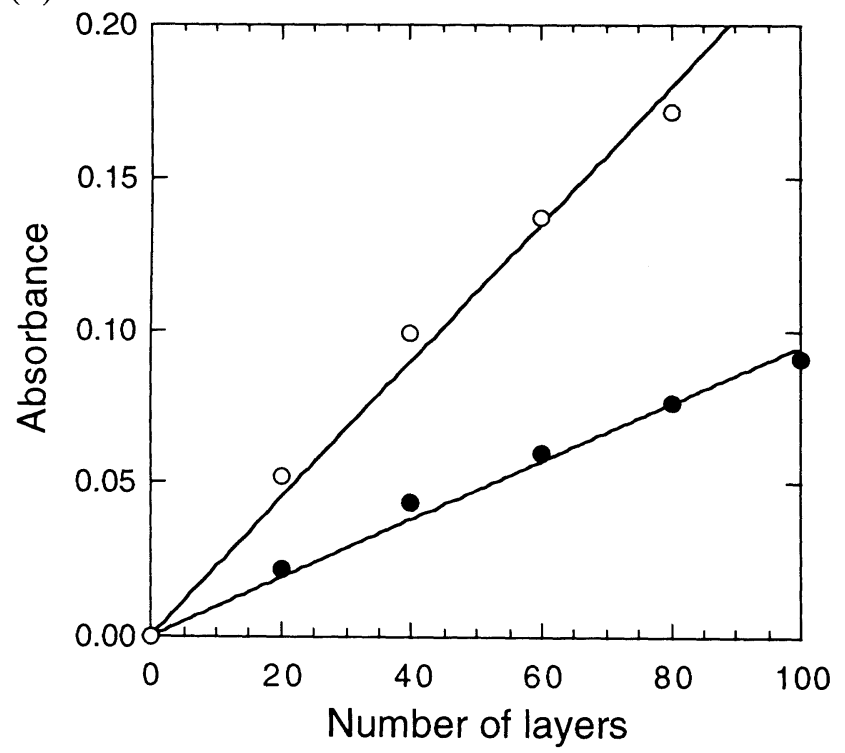

Figure 5. (a) UV-vis absorption spectra of $\mathrm{p}(\mathrm{DDA} / \mathrm{Rudpphen6)} \mathrm{LB}$ films from 20 to 80 layers and (b) plots of the absorption $(470 \mathrm{~nm})$ of $\mathrm{p}$ (DDA/Rudpphen6) (closed circle) and $\mathrm{p}$ (DDA/Rudpphen 14) (open circle) LB films as a function of the number of layers.

and $\mathrm{Ru}(\mathrm{dpphen})_{3}{ }^{2+}$ was spread on the water subphase at $\mathrm{pH}=7$. The monolayer was not stable, and the surface limiting area of $\mathrm{Ru}(\mathrm{dpphen})_{3}{ }^{2+}$ group was found to be even lower, $0.5 \mathrm{~nm}^{2} /$ unit. No significant interaction for stable monolayer formation occurs between positively charged $\mathrm{Ru}(\mathrm{dpphen})_{3}{ }^{2+}$ and neutral amphiphiles (DDA).

We have previously described polymer LB films containing ruthenium complex, Ru(bpy) ${ }_{3}{ }^{2+}(\mathrm{bpy}=2,2$ 'bipyridine), which is incorporated as a comonomer of the copolymerization method. ${ }^{6}$ The surface limiting area of $\mathrm{Ru}(\mathrm{bpy})_{3}{ }^{2+}$ moiety was estimated to be much smaller, ca. $0.01 \mathrm{~nm}^{2} / \mathrm{unit}$. The difference is attributed to the solubility in water; amphiphilic Ru(bpy) ${ }_{3}{ }^{2+}$ group enters into the water subphase (Figure 4(a)), while hydrophobic
$\mathrm{Ru}(\mathrm{dpphen})_{3}{ }^{2+}$ moiety lies in the hydrophobic portion of alkyl side chains occupying its own molecular area on the water surface $\left(1.11 \mathrm{~nm}^{2} / \mathrm{unit}\right)$. The $\mathrm{Ru}(\mathrm{dpphen})_{3}{ }^{2+}$ moieties would be densely packed between dodecyl alkyl side chains in the monolayer at the interface (Figure 4(b)).

\section{LB Film Formation}

The monolayers can be transferred onto a hydrophobic substrate at a surface pressure of $25 \mathrm{mN} / \mathrm{m}$, yielding Y-type LB films with a transfer ratio of unity. To confirm the introduction of the $\mathrm{Ru}(\mathrm{dpphen}){ }_{3}{ }^{2+}$ group into the polymer monolayer, the UV-vis absorption spectra of the LB films were measured. Figure 5(a) shows the UV-vis spectra of the LB films as a function of the number of deposited layers. The typical absorption band, observed at around $470 \mathrm{~nm}$, is attributed to the Metal to Ligand Charge Transfer (MLCT) band of the Ru(dpphen) ${ }_{3}{ }^{2+}$ group. Figure 5(b) shows the plots of the absorbance at $470 \mathrm{~nm}$ with the number of layers. A linear relationship can be obtained in both $\mathrm{p}$ (DDA/Rudpphen6) and p(DDA/ Rudpphen 14) LB films, indicating successive regular deposition of the monolayer. As for $\mathrm{p}(\mathrm{DDA} / \mathrm{Rudpphen6)}$ LB films, we evaluated the surface density of $\mathrm{Ru}$ (dpphen $)_{3}{ }^{2+}$ moieties in the LB film. The absorbance per monolayer of $\mathrm{p}(\mathrm{DDA} / \mathrm{Rudpphen6)}$ can be obtained from the slope of the straight line in Figure $5(\mathrm{~b})$ to be $9.49 \times 10^{-4}$. When the molar extinction coefficient $\varepsilon$ is assumed to be $3.00 \times 10^{4} \mathrm{M}^{-1} \mathrm{~cm}^{-1}$ at $470 \mathrm{~nm},{ }^{17}$ the molar concentration of $\mathrm{Ru}(\mathrm{dpphen})_{3}{ }^{2+}$ could be determined to be $3.16 \times 10^{-11} \mathrm{~mol} / \mathrm{cm}^{2}$ using Lambert-Beer's Law. From the $\pi-A$ isotherms, the surface molar concentration of $\mathrm{Ru}(\text { dpphen })_{3}{ }^{2+}$ was determined to be $3.02 \times 10^{-11} \mathrm{~mol} /$ $\mathrm{cm}^{2}$, which is consistent with the former one. This means that the $\mathrm{Ru}(\mathrm{dpphen}){ }_{3}{ }^{2+}$ residues are dispersed molecularly, without aggregation. In addition, all $\mathrm{Ru}(\mathrm{dpphen})_{3}{ }^{2+}$ molecules are tightly adsorbed by acrylate anions, and transferred onto the substrates. It is concluded that the $\mathrm{Ru}(\text { dpphen })_{3}{ }^{2+}$ chromophores are homogeneously introduced into the polymer monolayer by the electrostatic adsorption with acrylate anion groups.

The X-ray diffraction measurement was carried out for the LB film with 40 layers to investigate the layer structure of $\mathrm{p}(\mathrm{DDA} / \mathrm{Rudpphen6)} \mathrm{LB}$ films. Some Kiessig fringe and one Bragg peak patterns could be obtained, and the thickness for one layer was determined to be 1.77 $\mathrm{nm}$ from the Bragg peak (Figure 6). The length well corresponds to that of pDDA LB films. This also supports that the highly ordered layer structure would be formed even if the bulky $\mathrm{Ru}(\mathrm{dpphen})_{3}{ }^{2+}$ is incorporated in the LB films.

\section{Emission Quenching of $p(D D A / R u d p p h e n) L B$ films by Oxygen}

From the applicational point of view, Demas et al. ${ }^{17-19}$ and other research groups ${ }^{20,21}$ have intensively investigated the potential of ruthenium complexes as a luminescence-based optical sensor. Ruthenium complexes exhibit a high quantum yield, a long excited-state lifetime, and strong absorption in the blue-green spectral region. The luminescence can be easily quenched by oxygen. Recently, Gouterman investigated the oxygen quenching of luminescence as a pressure sensitive paint for wind tunnel research. ${ }^{22}$ We considered the potential 


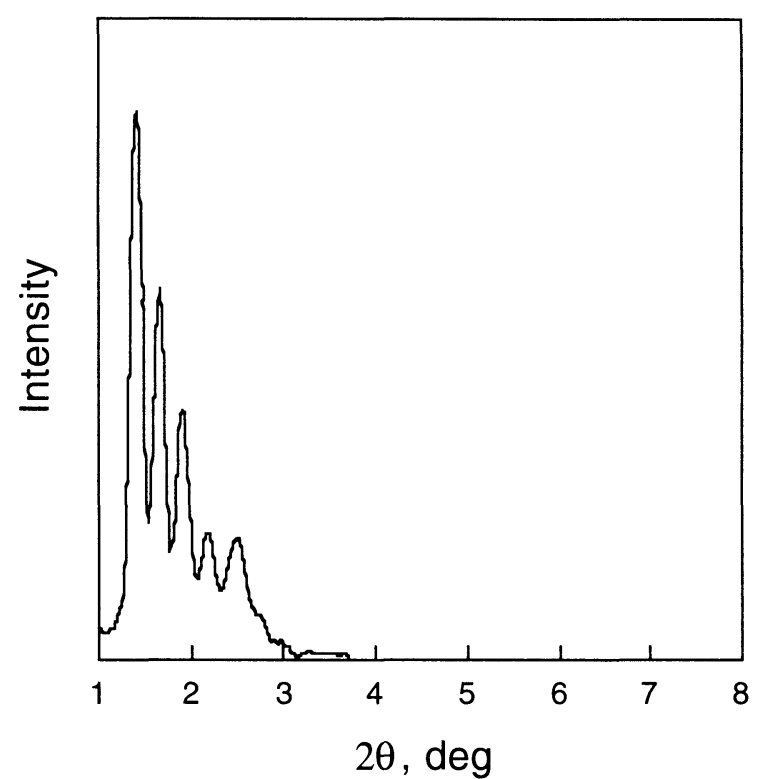

Figure 6. X-ray diffraction patterns of $p$ (DDA/Rudpphen6) LB films with 40 layers.

of the polyion complex LB films containing $\mathrm{Ru}(\mathrm{dpphen})_{3}{ }^{2+}$ as a two-dimensional ultrathin film sensor. Figure 7 shows the decay curve of the LB films consisting five pre-deposited layers of $\mathrm{pDDA}$ and a $\mathrm{p}(\mathrm{DDA} /$ Rudpphen6) monolayer $\left(\lambda_{\text {em }}=610 \mathrm{~nm}\right)$. The pDDA layers are firstly deposited as a protecting layer to prevent from suffering the substrate quenching. As shown in Figure 7 , the luminescence of $\mathrm{Ru}(\text { dpphen })_{3}{ }^{2+}$ is effectively quenched under the atmosphere of pure oxygen. The decay curve could not be analyzed by single exponential fitting. This implies that the ruthenium complexes of polymer LB films lie in the microheterogeneous media in view of luminescent quenching. In general, it seems to be difficult to address the relative contributions of luminescent quenching, e.g., static and dynamic quench-

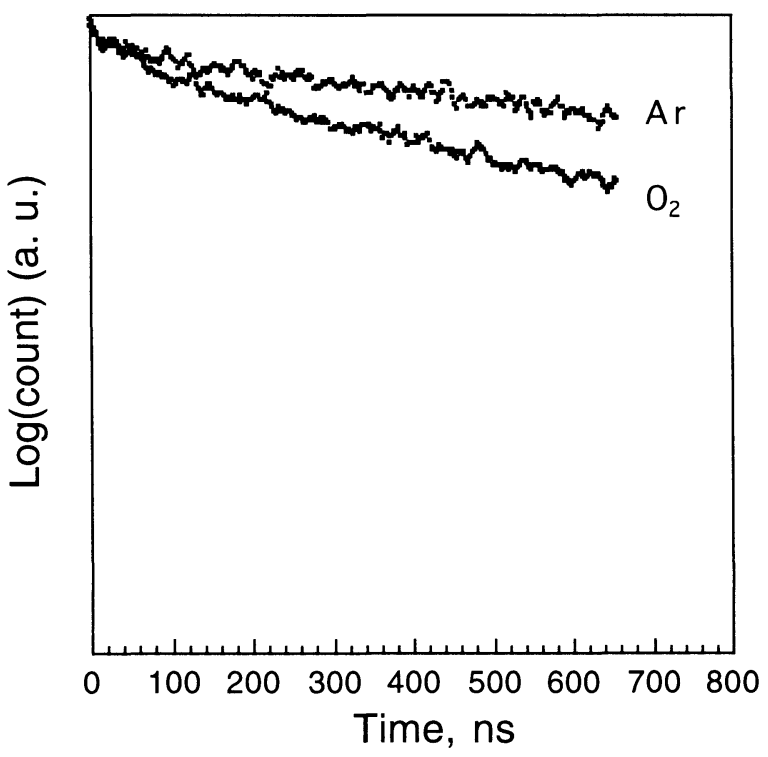

Figure 7. Time-resolved emission curves of $p(D D A / R u d p p h e n 6)$ LB films under the atmosphere of pure argon and oxygen. As for the layer structure, see the text.
Table II. Sensitivity to oxygen quenching of $\mathrm{p}$ (DDA/Rudpphen) LB films

\begin{tabular}{lrrc}
\hline & $\tau_{\mathrm{O}_{2}}(\mathrm{~ns})$ & $\tau_{\mathrm{Ar}}(\mathrm{ns})$ & $\begin{array}{c}\text { Quenching Efficiency } \\
\tau_{\mathrm{O}_{2}} / \tau_{\mathrm{Ar}}\end{array}$ \\
\hline $\mathrm{p}(\mathrm{DDA} /$ Rudpphen6) & 1200 & 2300 & 0.52 \\
$\mathrm{p}(\mathrm{DDA} /$ Rudpphen 14) & 600 & 1000 & 0.60 \\
\hline
\end{tabular}

ing. For simplicity, we used two exponential fitting and calculated averaged-lifetime using eq 1 .

$$
\begin{aligned}
& I(t)=a_{1} \exp \left(-t / \tau_{1}\right)+a_{2} \exp \left(-t / \tau_{2}\right) \\
& \tau_{\text {ave }}=\frac{\left(a_{1} \tau_{1}^{2}+a_{2} \tau_{2}^{2}\right)}{\left(a_{1} \tau_{1}+a_{2} \tau_{2}\right)}
\end{aligned}
$$

The results are listed in Table II. The lifetime of $\mathrm{Ru}(\text { dpphen })_{3}{ }^{2+}$ is very long, and rather sensitive to oxygen. The quenching efficiency of $p$ (DDA/Rudpphen) LB films was around $50 \%$.

\section{CONCLUDING REMARKS}

Our attempt to fabricate polyion complex LB films is based on the replacement reaction of SuOA group which is followed by the successive electrostatic adsorption between $\mathrm{Ru}(\mathrm{dpphen})_{3}{ }^{2+}$ and acrylate anions at the air/water interface. Polymer LB films containing Ru(dpphen) ${ }_{3}{ }^{2+}$ were prepared by spreading a chloroform solution of $\mathrm{p}(\mathrm{DDA} / \mathrm{SuOA})$ and $\mathrm{Ru}(\mathrm{dpphen})_{3} \mathrm{Cl}_{2}$ onto the water subphase at $\mathrm{pH}=11$. Of interest is the use of hydrophobic $\mathrm{p}(\mathrm{DDA} / \mathrm{SuOA})$ and $\mathrm{Ru}(\mathrm{dpphen})_{3}{ }^{2+}$, resulting in the stable polyion complex monolayer formation at the air/ water interface. The $\mathrm{Ru}(\mathrm{dpphen})_{3}{ }^{2+}$ molecules are considered to be densely packed in the hydrophobic part of polyion monolayer. The monolayer could be successfully transferred on a quartz substrate. We confirmed the uniform distribution of $\mathrm{Ru}(\mathrm{dpphen})_{3}{ }^{2+}$ and the highly ordered layer structure of $\mathrm{p}$ (DDA/Rudpphen) LB films with UV-vis spectroscopy and X-ray diffraction measurement. The luminescence of $\mathrm{p}$ (DDA/Rudpphen) LB films was rather sensitive to oxygen. Considering these facts, the $p$ (DDA/Rudpphen) LB films are expected to be a twodimensional ultrathin film sensor sensitive to oxygen. The pressure profile based on hydrodynamic flow might be visualized as a change in luminescent intensity with micrometer scale. From this point of view, the work is now in progress.

Acknowledgments. The authors acknowledge support by Grant-in-Aid for Scientific Research on Priority Areas, New Polymers and Their Nano-Organized Systems (No. 277/0910126206), from the Ministry of Education, Science, Sports and Culture of Japan and by the Research for the Future (JSPS-RFTF 97P00302) from the Japan Society for the Promotion of Science.

\section{REFERENCES}

1. T. Miyashita, Y. Mizuta, and M. Matsuda, Br. Polym. J., 22, 327 (1990). 
2. T. Miyashita, Prog. Polym. Sci., 18, 294 (1993).

3. T. Miyashita, J. Sakai, Y. Mizuta, and M. Matsuda, Thin Solid Films, 244, 718 (1994).

4. T. Miyashita, M. Matsuda, M. Van der Auweraer, and F. C. De Schryver, Macromolecules, 27, 513 (1994).

5. J. Matsui, M. Mitsuishi, and T. Miyashita, Macromolecules, 32, 381 (1999).

6. A. Aoki and T. Miyashita, Chem. Lett., 563 (1996).

7. K. Arisumi, F. Feng, T. Miyashita, and H. Ninomiya, Langmuir, 14, 5555 (1998).

8. E. D. Goddard and R. B. Hannan, J. Colloid Interface Surf., 19, 301 (1986).

9. H. Grüniger, D. Möbius, and H. Meyer, J. Chem. Phys., 79, 3701 (1983)

10. U. Lehmann, Thin Solid Films, 160, 257 (1988).

11. M. Shimomura and T. Kunitake, Thin Solid Films, 132, 243 (1985).

12. N. Nishiyama and M. Fujihira, Chem. Lett., 1257 (1988).
13. R. A. Hall, M. Hara, and W. Knoll, Langmuir, 12, 2551 (1996).

14. T. Seki, A.Tohnai, N. Tanigaki, K. Yao, T. Tamaki, and A. Kaito, Macromolecules, 30, 1768 (1997).

15. I. Fujita and H. Kobayashi, Ber. Bunsen-Ges. Phys. Chem., 76, 115 (1972).

16. T. Miyashita, T. Murakata, and M. Matsuda, J. Phys. Chem., 93, 1426 (1989).

17. W. Xu, R. C. McDonough, III, B. Langsdorf, J. N. Demas, and B. A. DeGraff, Anal. Chem., 66, 4133 (1994).

18. E. B. Carraway, J. N. Demas, D. A. DeGraff, and J. H. Bacon, Anal. Chem., 63, 337 (1991).

19. N. Watkins, B. R. Wenner, J. D. Jordan, W. Xu, J. N. Demas, and F. V. Bright, Appl. Spect., 52, 750 (1998).

20. K. P. McNamara, X. Li, A. D. Stull, and Z. Rosenzweig, Anal. Chim. Acta, 361, 73 (1998).

21. R. Herne, J. Brocas, and E. V. Donckt, Anal. Chim. Acta, 364, 131 (1998).

22. M. Gouterman, J. Chem. Educ., 74, 697 (1997). 